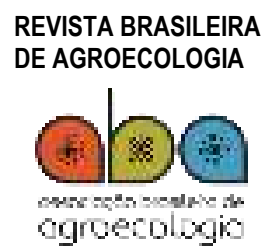

ISSN: $1980-9735$

DOI: $10.33240 /$ rba.v14i1.22904

Vol. 14 | No. $1 \mid$ p. 33-39| 2019

\title{
RECEPTIVIDADE DE TÉCNICAS DE CULTIVO SEM QUEIMA EM SISTEMA DE PRODUÇÃO FAMILIAR NA AMAZÔNIA ORIENTAL
}

Receptivity of crop practices without burning in family

production system of eastern Amazon

Francinaldo Ferreira de Matos', Paulo Fernando da Silva Martins ${ }^{2}$ e Luís Mauro Santos Silva²

${ }^{1}$ Associacão do Movimento Interestadual da Quebradeiras de Coco Babacú (AMIQCB), São Luís - MA - Brasil..

${ }^{2}$ Universidade Federal do Pará, Belém - PA - Brasil.

\section{Recebido em:}

22/01/2019

Aceito para publicação em: 30/03/2019

Correspondência para: pfsm@ufpa.br

\section{ABSTRACT}

Neste trabalho são analisados processos de adaptação, adoção e domínio de inovações técnicas de base agroecológica em estabelecimentos agrícolas familiares localizados na periferia da Amazônia Oriental. É dada ênfase nas inovações técnicas empregadas no processo produtivo das culturas anuais essenciais à alimentação, em associação com a preservação do babaçual. A unidade de análise é o estabelecimento familiar em parcelas de roça queimada e de roça sem queimada. A aceitação ou rejeição integral/parcial das inovações técnicas depende de diversos fatores, mas aquelas que estão ligadas à roça sem queima são as de mais difícil assimilação, por provocarem mudanças profundas no sistema de produção.

Palavras-chave: Agricultura Itinerante. Estabelecimento Rural. Processo Inovativo.

\section{RESUMO}

In this paper are analysed the processes of adaptation, adoption and mastery of technical innovations in ecologically-based family farms located on the eastern Amazon. Is given emphasis for technical innovations employed in the productive process of annual crops associated to babaçu. The unit of analysis is the family farm with burned and unburned plots. The acceptance or rejection of all or a part of the technical innovations depends on several factors. However, those that are linked to unburned plots are the most difficult to assimilate, probably because they cause deeper changes in the production system.

Keywords: Shifting Cultivation. Farm. Innovative Process. 
No início da década de 1990, ocorreu o aprofundamento da crise ecológica global ligada à progressiva degradação da natureza e à desigualdade social no acesso aos meios de produção (FREITAS, 2004). Essa crise foi provocada pela adoção de sistemas de produção fundamentados na lógica de produção baseada pelo no intensivo de insumos químicos e aportes externos à propriedade (EHLERS, 1999). No âmbito da Amazônia oriental, isso provocou profunda modificação tecnológica nos sistemas produtivos, com poucos cuidados aos aspectos socioambientais (FREITAS, 2004).

Na periferia da Amazônia oriental, zona de transição entre o bioma de floresta e cerrado, as famílias do campo dependem do extrativismo de produtos da palmeira de babaçu (Orbignya phalerata Mart.) e da roça de cultivos essenciais na alimentação dos agricultores: arroz (Oryza sativa L.), milho (Zea Mays L.), feijão (Phaseolus vulgaris L.) e mandioca (Manihot esculenta Crantz). Porém, o aumento da pressão sobre a biodiversidade, causado pelo uso intensivo de insumos químicos e aportes externos à propriedade, tem forçado a busca por soluções compatíveis com a preservação do meio ambiente.

A substituição do sistema de produção tradicional da roça queimada (RQ), depois de intervalos de pousio, na mesma área, pela roça sem queima (RSQ), é uma proposta que possibilitaria o cultivo das culturas de arroz, milho, feijão e mandioca combinada com a manutenção da palmeira de babaçu, sem utilização de queimadas, agroquímicos, sementes híbridas e sem o revolvimento do solo (ASSEMA, 1998). Nesse sentido, a substituição da RQ pela RSQ tem sido proposta aos agricultores pela Cooperativa dos Pequenos Produtores Agroextrativistas de Lago do Junco (COPPAL), município do estado do Maranhão, como uma inovação técnica (ASSEMA, 2006). Uma inovação técnica pode ser originada tanto da agricultura industrial quanto da agricultura de base ecológica. Contudo, para ser adotada, precisa ser entendida, aceita e dominada pelo agricultor (LEFORT, 1990).

O presente trabalho tem o objetivo de analisar a inserção das inovações em torno da RSQ no sistema de produção dos agricultores familiares do município de Lago do Junco, estado do Maranhão, considerando as etapas do processo de adaptação (ajustes e abandono), adoção e domínio das inovações técnicas contidas na proposta da roça sem queima, conforme Lefort (1990). Esse autor considera o domínio pelo agricultor como a consolidação de uma inovação técnica, depois de um processo não linear (KNICKELA et al., 2008; SABOURIN, 2004) e que inicia pela tentativa de adaptação da mesma em seu sistema de produção (OLIVEIRA e ROCHA, 2010).

O município de Lago do Junco pertence à Microrregião Médio Mearim situada na região geográfica próxima à parte central do Estado do Maranhão. Trata-se de área de transição entre o bioma Amazônico, caracterizado por vegetação de matas com forte presença de palmeira de babaçu (Attalea speciosa Mart.) e o bioma de Cerrado. A proposta de RSQ incluiu apoio financeiro aos agricultores, os quais se dispuseram a experimentá-la. Esse apoio ocorreu nos três primeiros anos de execução das atividades correspondentes a cem diárias distribuídas em quarenta diárias no primeiro e segundo anos, e vinte diárias no terceiro ano. Foram realizadas entrevistas com os agricultores obedecendo ao método de escolha aleatória, com universo amostral de 25 agricultores familiares experimentadores da RSQ, que foram divididos em dois grupos: a) 14 agricultores persistentes na execução da proposta da RSQ, equivalente a $56 \%$ da amostra; e b) 11 agricultores desistentes, que correspondem a $44 \%$ do espaço amostral. Os instrumentos de coleta de dados e informações foram o questionário com entrevistas semidirigidas, segundo Quivy e Campanhoudt (1998) e a observação não participante, conforme Barros e Lehfeld (1990), efetuados nos ciclos agrícolas de 2000/2001 a 2009/2010.

A análise foi realizada considerando a assimilação das técnicas de roça sem queima através das possíveis etapas, sucessivas ou não, de adaptação, adoção e domínio de inovações técnicas nos estabelecimentos familiares que as experimentaram. Segundo Lefort (1990), a etapa denominada "adaptação" corresponde ao processo de assimilação, em que as tecnologias provenientes da pesquisa, ou de outras fontes, precisam, na maioria das vezes, ser ajustadas, modificadas, harmonizadas ou, ao contrário, abandonadas. Na etapa de "adoção", a inovação já se apresenta como aceitável por se articular com os elementos do sistema de produção, correspondendo à etapa de testes e de ajustes da inovação. Na etapa de "domínio", a inovação introduzida já se encontra integrada ao conhecimento e às práticas dos agricultores. 
As inovações técnicas analisadas foram organizadas em dois grupos: (a) as de natureza técnico-produtiva e ambiental; e (b) as de natureza técnico-gerencial. As inovações do primeiro grupo são as inovações que têm relações diretas com a terra como fator de produção e com a conservação dos recursos naturais. Elas influem no processo produtivo, favorecendo ou restringindo a eficiência reprodutiva do estabelecimento familiar. As do segundo grupo são as inovações relacionadas aos processos de gerenciamento do estabelecimento rural, com potencial para influenciar positiva ou negativamente no processo produtivo familiar.

A proposta técnica da RSQ foi uma tentativa de encontrar alternativa produtiva ao cultivo da RQ. As inovações técnicas da RSQ e suas etapas de inclusão no processo produtivo, social e ambiental dos estabelecimentos familiares são, aqui, analisadas a partir dos percentuais de adaptação (ajustes ou abandono), adoção e domínio pelos agricultores, estando contidos na Tabela 1.

A técnica de preparo do solo sem o uso de queimada, buscou eliminar queimadas descontroladas e recuperar a fertilidade do solo. Dos agricultores entrevistados na fase de adaptação, $12 \%$ tentaram ajustá-la, enquanto $40 \%$ a abandonaram. Dos demais, $12 \%$ chegaram a adotá-la, mas só $36 \%$ chegaram a dominá-la. Destes últimos, $11 \%$ a utilizam apenas no cultivo do feijão. É na etapa de adoção que o agricultor faz os ajustes necessários na inovação, com inserção parcial ou total no sistema de produção (OLIVEIRA e ROCHA, 2010). Dos $40 \%$ que abandonaram o preparo do solo da roça sem queima, a maioria possuía idade mais avançada e os que conseguiam satisfazer as necessidades de consumo dos membros da família com uma renda adicional obtida de benefícios sociais. , corroborando que as condições socioeconômicas dos agricultores são fundamentais para adoção ou rejeição de inovações técnicas (FREITAS, 2004; OLIVEIRA e ROCHA, 2010).

A técnica de manejo de plantas adubadeiras foi realizada por meio do seu plantio no interior e no perímetro da parcela da RSQ, utilizando espécies vegetais de crescimento rápido que admitem cortes frequentes, como feijão de porco (Canavalia ensiformis DC.), feijão guandu (Cajanus cajan (I.) millsp.) e urucum (Bixa orellana L.). Não houve nenhum agricultor que chegasse a dominar essa técnica, que teve como objetivo assegurar a recuperação da fertilidade do solo mantendo-o coberto o ano todo, pela reposição da matéria orgânica na forma de adubação verde e de adubação de cobertura. Uma parte deles chegou na etapa de adoção e a maior parte abandonou-a, ficando a minoria na etapa de ajuste.

Tabela 1. Indicação da intensidade de assimilação das inovações técnicas da Roça sem Queima (RSQ) pelos agricultores familiares do Município de Lago do Junco, Estado do Maranhão, nas diferentes etapas do processo. Inovações técnicas $\quad$ Agricultores $(\mathrm{N}=25)$ nas etapas de assimilação das inovações técnicas (\%)

\begin{tabular}{|c|c|c|c|c|}
\hline \multirow[t]{3}{*}{ Inovações técnicas } & \multicolumn{4}{|c|}{$\begin{array}{c}\text { Agricultores ( } \mathrm{N}=25) \text { nas etapas de assimilação das } \\
\text { inovações técnicas (\%) }\end{array}$} \\
\hline & \multicolumn{2}{|c|}{ Adaptação } & \multirow[t]{2}{*}{ Adoção } & \multirow[t]{2}{*}{ Domínio } \\
\hline & Ajuste & Abandono & & \\
\hline \multicolumn{5}{|c|}{ 1) DE NATUREZA TÉCNICO-PRODUTIVA E AMBIENTAL } \\
\hline Preparo do solo sem uso de queimada & 12 & 40 & 12 & 36 \\
\hline Plantio e manejo de plantas adubadeiras & 12 & 60 & 28 & 00 \\
\hline Controle alternativo de insetos indesejados & 04 & 32 & 28 & 36 \\
\hline Controle de queimadas & - & - & - & 100 \\
\hline Seleção de sementes & - & - & - & 100 \\
\hline Conservação dos babaçuais & - & - & - & 100 \\
\hline Conservação da área de reserva legal & - & - & 44 & 56 \\
\hline Conservação dos recursos hídricos & - & - & 60 & 40 \\
\hline \multicolumn{5}{|l|}{ 2) DE NATUREZA TÉCNICO-GERENCIAL } \\
\hline Participação da mulher na gestão RSQ & 20 & 00 & 56 & 24 \\
\hline Registro de informações do estabelecimento & 52 & 44 & - & 04 \\
\hline Planejamento das parcelas de produção & 28 & - & 24 & 48 \\
\hline
\end{tabular}


Os agricultores que não conseguiram chegar na etapa de adoção (72\%), no manejo de plantas adubadeiras, experimentaram e ajustaram essa inovação por um período de nove anos, sem conseguir dominá-la, mesmo aqueles que a utilizaram por três ciclos agrícolas. Por outro lado, os $12 \%$ de agricultores que tentaram ajustá-la, renunciaram após testá-la em um único ciclo agrícola. Os que ficaram na etapa de adoção (28\%) plantam e manejam o urucum e o feijão guandu, enquanto $12 \%$, situados na etapa de ajuste, pararam ao analisar os riscos inerentes à mão-de-obra familiar disponível e o retorno que esta inovação pode propiciar, corroborando ser nessa etapa que os agricultores ajustam a inovação segundo sua situação econômica e a condição agroecológica do estabelecimento, vindo a considerar, essencialmente, os custos, os riscos e os resultados que poderão ser obtidos (OLIVEIRA e ROCHA, 2010).

As técnicas de controle ecológico de insetos indesejados foram aplicadas visando o controle preventivo e o controle curativo de situações já instaladas. O controle preventivo foi feito através da criação de um ambiente propício aos inimigos naturais dos insetos indesejados e à nutrição adequada das espécies cultivadas. No controle do percevejo vermelho (Crinocerus sanctus) do feijão, foram utilizados a urina de vaca e o neem (Azadirachta indica A. Juss.), cuja aplicação resultou em uma assimilação em que $4 \%$ dos agricultores ficaram na fase de ajuste, $32 \%$ abandonaram, $28 \%$ adotaram e $36 \%$ as dominaram.

No controle de insetos, os $28 \%$ dos agricultores que chegaram à etapa de adoção, incluíram agricultores iniciantes no cultivo das culturas anuais na RSQ, que utilizaram essa técnica, principalmente, nas hortaliças e na cultura do feijão. Quase a metade dos que utilizam técnicas de controle declaram usar produtos químicos quando da baixa eficiência dos controles agroecológicos experimentados, especialmente no caso das saúvas e outros insetos que causam prejuízos nos cultivos do arroz, o percevejo (Tibraca limbativentris Stal) e do caupi, o percevejo-vermelho-do-caupi (Crinocerus sanctus) e a patriótica (Diabrótica speciosa).

As técnicas de controle de queimadas, que tiveram o objetivo de evitar que o fogo ultrapassasse os limites da área manejada e provocasse prejuízos econômicos e ecológicos na área de capoeira, de pastagens, de reserva legal e de plantações, foram dominadas por todos os agricultores.

Os agricultores que experimentaram o controle da queimada na RSQ acabaram por incluir essa inovação, também, no preparo do solo para plantio na RQ. A construção de aceiros era uma prática não desenvolvida pela maioria destes agricultores antes de conhecerem a proposta da RSQ. Fato confirmado pelo registro de constantes acidentes de queimada desnecessária nas áreas de pastagens, de plantios, de reservas legais e de capoeiras da região. Constatou-se, então, que o uso de aceiros é uma prática que foi resgatada e dominada pela totalidade dos agricultores analisados.

A seleção de semente para o plantio da safra seguinte, que teve o objetivo de proteger e conservar o patrimônio genético local, evitando a dependência dos agricultores e a entrada de sementes híbridas no sistema de produção familiar, também foi dominada por todos agricultores, inclusive os que tinham abandonado essa prática no passado. Essa prática se deu, sobretudo, na seleção de sementes das culturas de arroz, milho, feijão e mandioca, que são as principais da alimentação regional, conforme destacam CAA-NM (2008), bem como Paulino e Gomes (2015) entre outros.

A conservação dos babaçuais possibilita garantir às famílias o extrativismo do coco babaçu, por meio da reposição das palmeiras adultas pelas palmeiras jovens (Pindovas). Ela foi efetuada deixando, no mínimo, 60 palmeiras adultas e 60 palmeiras jovens, por hectare, nas áreas de pastagens e de cultivos. Essa inovação evita o uso de produtos químicos nas Pindovas, o corte do cacho verde e o descontrole das queimadas e das derrubadas de palmeiras. Na assimilação desta prática, todos os agricultores chegaram à etapa domínio, pois todos mantiveram o manejo das Pindovas e a conservação dos babaçuais.

A conservação da área de reserva legal teve a finalidade de preservar áreas que devem ficar sem utilização para manter as condições de vida favorecendo diferentes espécies de plantas e animais, bem como auxiliando na manutenção do equilíbrio ecológico do estabelecimento familiar (AMARAL e 
NETO, 2005). A maioria dos agricultores (56\%) atingiu a etapa de domínio dessa técnica. Esses agricultores são os que possuem área de reserva legal nas terras de gestão individual, além de gestão coletiva, enquanto os que só chegaram à etapa de adoção (44\%) possuem reserva legal somente na terra de gestão coletiva.

A conservação dos recursos hídricos visou a preservação dos igarapés, lagoas, lagos, açudes e nascentes existentes nos estabelecimentos familiares, com a manutenção e recuperação da mata ciliar. Do universo pesquisado, nenhum agricultor abandonou essa prática e a maioria (60\%) a conduziu até a etapa de adoção, garantindo a proteção dos recursos hídricos localizados nas terras de gestão individual e nas terras de gestão coletiva, enquanto $40 \%$ dos agricultores chegaram até a etapa de domínio, sendo que, na proteção das terras de gestão coletiva, isso se deveu aos acordos coletivos. Nelas, as fontes de água geralmente não estavam protegidas, principalmente nas localizadas em áreas de pastagens e de capoeiras utilizadas para o cultivo da RQ.

Das inovações de natureza técnico-produtiva e ambiental, relacionadas ao aumento ou manutenção da produção, as que menos atingiram as etapas de adoção e de domínio foram as mais diretamente vinculadas à RSQ, incluindo o preparo do solo, o uso de plantas adubadeiras e o controle alternativo de insetos indesejados (Tabela 1). Essas técnicas são de difícil controle e de forte concorrência com as técnicas mais eficientes de uso de insumos químicos (ELHERS, 1999; FREITAS, 2004; OLIVEIRA e ROCHA, 2010), mas que são desfavoráveis à qualidade do meio ambiente. Por outro lado, o controle das queimadas, a seleção de sementes e a conservação dos babaçuais são as técnicas que mais foram inseridas nos estabelecimentos familiares.

A conservação dos babaçuais é de grande importância para o desenvolvimento sustentável (MARQUES e BRITO, 2014), Das inovações mais implicadas na conservação dos recursos naturais, a conservação dos babaçuais foi a mais inserida nos estabelecimentos agrícolas, seguida da conservação da reserva legal e a de preservação dos recursos hídricos (Tabela 1).

A avaliação da participação da mulher no contexto rural se impõe como uma necessidade (SILVA e SCHNEIDER, 2010). No caso da gestão e execução da proposta da RSQ essa participação está presente representando uma descentralização das informações e das decisões do processo produtivo, geralmente concentradas nos homens chefes de famílias. Houve participação da mulher em $20 \%$ dos estabelecimentos na etapa de ajuste, $56 \%$ na de adoção e $24 \%$ na de domínio, não tendo havido famílias em que a participação da mulher deixou de ocorrer. Das famílias que estão na etapa de adoção, a gestão do processo produtivo esteve dividida entre a mulher e o homem, contudo ela ficou responsável pela RSQ e ele pela $\mathrm{RQ}$.

O registro de informações do estabelecimento familiar visou a obtenção dos dados do trabalho dos componentes da família e dos produtos colhidos na RQ e na RSQ e das demais atividades agropecuárias e extrativistas desenvolvidas, no decorrer do ciclo agrícola. Os registros compreenderam os dias trabalhados, as despesas realizadas, a produção obtida, a consumida e a comercializada. Dentre os agricultores que realizaram os registros, poucos chegaram a dominá-lo $(4 \%)$, os que estão na etapa de ajuste (52\%) fazem apenas os registros sobre a parcela da RSQ, mas na fase inicial do processo. Enquanto que $44 \%$ abandonaram essa inovação logo após o fim do subsídio financeiro, evidenciando, por um lado, a falta de recursos financeiros para promover inovações dos agricultores familiares (OLIVEIRA e ROCHA, 2010) e, por outro, a ausência de possibilidades de investimento decorrente da forma de produção independente inserida no sistema capitalista (JONES e BRESSAN, 2000).

O planejamento das parcelas de produção objetivou delinear as parcelas produtivas do estabelecimento, com definição de áreas fixas para o desenvolvimento das atividades de cultivos, criações e de conservação, visando o melhor aproveitamento das potencialidades existentes no estabelecimento familiar. A parcela de agricultores que chegaram à etapa de domínio correspondeu a $48 \%$, enquanto $24 \%$ a realizam de maneira informal. Os que estão na etapa de ajustes correspondem a $28 \%$, mas eles apenas planejaram as atividades relacionadas às roças, tanto RQ como RSQ, demonstrando que essa inovação teve pequena influência na melhoria do processo de gestão do estabelecimento como um todo. 
No que diz respeito às inovações de natureza técnico-gerencial, o planejamento das parcelas de produção, foi o que obteve maior nível de assimilação. Enquanto o registro de informações do estabelecimento ficou com o menor, provavelmente devido à cultura de informalidade que domina os processos gerenciais dos estabelecimentos familiares estudados. Esta informalidade nos estabelecimentos de natureza familiar decorre, pela falta de formação acadêmica dos seus membros, ainda comum no campo e, também, pela sua impessoalidade e menor burocracia (GRZYBOVSKI e TEDESCO, 2000) decorrente da estrutura descentralizada que favorece a aprendizagem organizacional orientada pela etnicidade e subsistemas culturais (GRZYBOVSKI, 2007)

As inovações técnicas que ficaram com mais frequência na etapa de ajuste foram o registro de informações do estabelecimento e o planejamento das parcelas de produção. As mais abandonadas foram o plantio e manejo de plantas adubadeiras e o preparo do solo sem uso de queimadas. As inovações que mais chegaram à etapa de adoção foram a conservação de recursos hídricos, a participação da mulher na gestão da RSQ e a conservação da reserva legal. Porém, as inovações que mais foram dominadas e inseridas no sistema de produção foram o controle de queimadas, a seleção de sementes e a conservação dos babaçuais.

As inovações mais difíceis de serem plenamente inseridas no sistema de produção dos agricultores, foram aquelas ligadas à modalidade de roça sem queima (RSQ), quer essa inovação possuísse uma ligação direta com esse tipo de roça, como nos casos do preparo do solo, do uso de plantas adubadeiras ou do controle alternativo de insetos indesejados, ou uma ligação indireta, como no caso da conservação dos recursos hídricos.

A pesquisa permite concluir que as inovações ligadas à roça sem queima provocaram a reorganização das atividades executadas, especialmente quando o tamanho do estabelecimento familiar é pequeno, acarretando na redução do tempo de pousio do solo e causando o aumento do trabalho, além da redução da produtividade dos cultivos da roça. Daí a dificuldade de inserção dessas inovações de característica agroecológica nos sistemas de produção em substituição aos da roça com queima.

\section{Referências}

AMARAL, P.; NETO, M. A. Manejo Florestal Comunitário: processos e aprendizagens na Amazônia Brasileira e na América Latina. Brasília: IEB, $2005 . \quad 84 \quad$ p. http://www.mma.gov.br/estruturas/pnf/ arquivos/mfc imazon.pdf Acesso em: 28 mar. 2019.

ASSOCIAÇÃO EM ÁREAS DE ASSENTAMENTO NO ESTADO DO MARANHÃO - ASSEMA. Proposta Experimental. Projetos exploração sustentada de lavouras de subsistência consorciadas com Palmeiras babaçu em Esperantinópolis - Maranhão. São Luís: ASSEMA. 1998. 25p.

Projeto Roças Orgânicas, Sustentabilidade da Vida na região dos Babaçuais Maranhenses. Pedreiras: ASSEMA. 2006. 16p.

BARROS, A. J. P.; LEHFELD, N. A. S. Projeto de pesquisa: propostas metodológicas. Petrópolis: Vozes, 1990. 102p. GRZYBOVSKI, D.; TEDESCO, J.C. Empresa Familiar: tendências e racionalidades em conflito. Passo Fundo: EDIUPF, 2000. 256p.

GRZYBOVSKI, D. Plataforma de conhecimentos e aprendizagem organizacional em empresas familiares. 2007. 383 p. Tese (Doutorado em Administração) - Programa de Pós-Graduação em Administração, Departamento de Administração e Economia, Universidade de Lavras, Lavras, 2004. Disponível em < http://repositorio.ufla.br/bitstream/1/2940/2/TESE Plataforma\%20de\%20conhecimentos\%20e\%20aprendizagem \%20transgeracional\%20em\%20empresas\%20familiares.pdf> Acesso em: 02 abr. 2019.

EHLERS, E. Agricultura sustentável: origem e perspectivas de um novo paradigma. 2. ed. Guaíba: Agropecuária, 1999. 157p.

FREITAS, A. C. R. Crise ecológica e mudança técnica da agricultura camponesa de derruba e queima da Amazônia Oriental. 2004. 170p. Tese (Doutorado em Desenvolvimento Sustentável do Trópico Úmido) - Universidade Federal do Pará, Belém, 2004.

JONES, A. S.; BRESSAN, M. Produção familiar, pós-modernidade e capitalismo:possibilidades da agricultura independente. Agroecologia e Desenvolvimento rural Sustentável. Porto Alegre, v. 1, n. 1, p. 39-45, 2000. Disponível em:

<http://www.emater.tche.br/docs/agroeco/revista/n1/07 artigo prod fam.pdf> Acesso em: 01 abr. 2019. 
LEFORT. J. Inovações tecnológicas e experimentação no meio rural. Tradução de J. L. DUBOIS. Brasília - DF: DAS/CIRAD/CPAC/EMBRAPA., 1990. 12p

KNICKELA, K.; et al. Towards a conceptual framework for agricultural and rural innovation policies. In: EUROPEAN IFSA SYMPOSIUM, 8., Clermont-Ferrand (France): IFSA. Anais .... Clermont-Ferrand (France), 2008. $883-893$. Disponível em: <http://ifsa.boku.ac.at/cms/fileadmin/Proceeding2008/2008 WS6 10 Knickel.pdf> Acesso em: 02 abr. 2019.

CENTRO DE AGRICULTURA ALTERNATIVA DO NORTE DE MINAS - CAA-NM. Produzindo sementes agroecológicas em sistemas diversificados de produção. Montes Claros: CAA-NM, 2008, 28 p.

OLIVEIRA, E. E. S. de; ROCHA, C. G. S. Inovações nas práticas agrícolas de agricultores familiares do sudoeste do Pará, Brasil. In: CONGRESSO DA SOCIEDADE BRASILEIRA DE SISTEMAS DE PRODUÇÃO. 8., 2010, São Luiz. Anais .... São Luís: UEMA, 2010. p.23-47.

MARQUES, G. P.; BRITO, E. P. de. A importância dos babaçuais na baixa bacia hidrográfica do Rio Mosquito em Palmeiras do Tocantins. Revista Interface (ISSN 1806-6062). n.7. 2014. p. 1-10.

PAULINO, J. S.; GOMES R. A. Sementes da Paixão: agroecologia e resgate da tradição. RESR, v. 53, n. 3, p. 517-528, 2015

QUIVY, R.; CAMPENHOUDT, L. V. Manual de investigação em ciências sociais. Tradução de João Minhoto Marques, Maria Amália Mendes 2. ed. Lisboa: Gradiva, 1998. 282p.

SABOURIN, E.; et al. Production d'innovations en partenariat: une experience dans l'agreste de la Paraiba, Brésil. In: CANEILL, J. (Ed.). Agronomes et innovations. Paris: L'Harmattan, 2004. p. 191-206.

SILVA, C. B. C; SCHNEIDER, S. Gênero, Trabalho rural e Pluriatividade. In: SCOTT, P.; CORDEIRO; R.; MENEZES, M. Gênero e Geração em Contextos Rurais. Florianópolis: Ed. Mulheres, 2010. p. 183-207. 